\title{
Multi-Indicator Intelligent Monitoring of Clinical Observations to Reduce Cesarean Section
}

\author{
Shasha Xie $\mathbb{D D}^{1},{ }^{1}$ Wei Dong $\left(\mathbb{D},{ }^{1}\right.$ Yeting Liu $\mathbb{D}^{2},{ }^{2}$ Haixiao Gao $\mathbb{D}^{3},{ }^{3}$ and Dan Zhang $\mathbb{D}^{3}$ \\ ${ }^{1}$ Affliated Xingtai People's Hospital of Heibei Medical University, Xingtai 054000, Hebei, China \\ ${ }^{2}$ The Third Hospital of Xingtai City, Xingtai 054000, Hebei, China \\ ${ }^{3}$ The First Affliated Hospital, Xingtai Medical College, Xingtai 054000, Hebei, China \\ Correspondence should be addressed to Dan Zhang; 201703320@stu.ncwu.edu.cn
}

Received 24 September 2021; Accepted 26 October 2021; Published 24 November 2021

Academic Editor: Yuvaraja Teekaraman

Copyright (c) 2021 Shasha Xie et al. This is an open access article distributed under the Creative Commons Attribution License, which permits unrestricted use, distribution, and reproduction in any medium, provided the original work is properly cited.

In order to analyze multi-index monitoring and the effect of reducing cesarean section, this paper selects March 2018 and March 2019 in two obstetrics and gynecology hospitals, referred to as hospital A and hospital B. As research objects, 313 pregnant women were divided into multi-index group and conventional group, while analyzing various indicators of each group of cesarean collection. The results show that the total CNAXE rate was $48.10 \%$ and $39.29 \%$, respectively, for 2018 and 2019, respectively, and the cesarean section of the conventional group was $65.75 \%$ and $63.64 \%$. By contrasting data of multi-index group and conventional group, hospital B differences were significant $(P<0.05)$, and hospital A difference was extremely significant $(P<0.01)$. In Cesarean section, obstetric sectors can help maternal treatment strategies by monitoring a series of related indicators for maternal to reduce Cesarean section and improve prognosis.

\section{Introduction}

In obstetric clinical treatment, cesarean section (CS) is a more common surgical method in the clinical treatment of obstetrics, is an effective means of solving difficulties, and has an important role in the treatment of high-risk pregnancy. However, as the ratio of Cesarean section continues to rise, the long-term short-term adverse prognosis of Cesarean section is increasingly prominent; Cesarean section is a scientific medical measure, and its role is to promote people's health; in order to ensure this, the goal requires reasonable use of Cesarean section in the actual population. If cesarean section is misused and abused, it will not only affect the efficiency of medical resources, but also increase the economic burden of pregnant women, but also have a great impact and risk on the health of mothers and infants. According to World Health Organization, the Sampling of Asian Country 2007-2008 was published in the "Willow Knife." The total percentage of Cesarean section in Asia is $27.3 \%$, with China contributing up to $46.2 \%$. The percentage of Cesarean section in USA was only $5.5 \%$ in the $1970 \mathrm{~s}$, which is the same as that of China in the same period, and it has risen to $25 \%$ in the late 1980 s. It was nearly 5 times in the 1970s; the percentage of Cesarean section in UK was 6\%-8\%, and, with slow rise, in the 1990s, the Cesarean section exceeded $20 \%$ of the Cesarean market rate; so far, Brazil, South America, has been the highest in the world, reaching $50.8 \%$ in 1994, and in 1996 the ratio was still as high as $36.4 \%$. According to relevant studies, if the probability of the pregnant woman's Cesarean section is greater than $30 \%$, the harm of the mother and child is increasing when using the Cesarean section. According to relevant reports, the United States had 2.2 people in the mortality rate of pregnant women in Cesarean section from 2000 to 2006, and the mortality rate of vaginal delivery is 0.2 people in every 100,000 people. Therefore, compared with the vaginal childbirth, it is not very safe. There is a possibility of causing a variety of complications to pregnant women using $\mathrm{Ce}-$ sarean section. For example, in surgery, anesthesia is unexpected, due to the bleeding, infection, and supine of low blood pressure in the uterine contraction, as well as the syndrome of low blood pressure; in surgery, the pregnant 
woman is prone to puerperium infection, postpartum hemorrhage (PPH), low back pain, lactation, pelvic or lower extremitic thrombosis, advanced postpartum bleeding, endometriosis, endometriosis, and so forth. Pregnant women are prone to placenta previa, placental detachment, ectopic pregnancy, and uterine injury. Compared with newborns from normal childbirth, infants who are born by Cesarean section are prone to wet lungs, hospitality premature birth, neonatal pulmonary transparent film disease, newborns jaundice, low immunity, childhood sensory issues and disorders, and bronchial asthma. Such a series of complications increase the proportion of newborns admitted to NICU. As a qualified medical staff, we should strictly follow the instructions of Cesarean section surgery, while the public should also understand the advantages and disadvantages of Cesarean section, try as possible the process of natural delivery, and reduce unnecessary Cesarean sections; in particular, the surgical indications for Cesarean section must be strictly grasped [1].

\section{Literature Review}

In recent years, due to the increase in Cesarean section, the number of maternal women with "scar uterus" has increased year by year. According to relevant reports, the repetitive Cesarean section rate of pregnant women in China has reached $92.5 \%$. According to relevant foreign literature, pregnant women can perform vaginal test production after Cesarean section, and success rate can reach $60 \%-80 \%$. With the changes in medical environment and the implementation of the family planning policy advocated by China, the proportion of Cesarean section of "nonmedical indications" is increasing, because the pregnant women and their families have insufficient understanding of Cesarean section. Forever scar uterus will lead to subsequent pregnancy pathological conditions and second Cesarean section (SSC) (duplicate Cesarean section, DSC), front placenta (Placenta Previa), $\mathrm{PP})$, placental implantation, and so forth, as well as the emergence of serious complications that endanger the safety of the mother and children. Recently, how to safely reduce the Cesarean section has become an important topic of the current obstetrics and requires multidisciplinary actions, including research on science and anesthesiology. The famous medical researcher Zhang $\mathrm{L}$. and colleagues have carried out a study on past Cesarean section. It is believed that the rise of Cesarean section is the culprit of women in various complications, such as consolidating hypertension or concurrent diabetes. Therefore, it is suggested that women choose natural delivery in the actual mode of delivery [2]. The famous medical researchers Gassama O. and colleagues believe that the change in Cesarean section happens with the changes in medical technology, socioeconomic development, and pregnant women's understanding of childbirth [3]. Therefore, the study of the indication of Cesarean section cannot be just in one year; there should be a valid analysis of multiyear data. In the case of foreign Cesarean section research, China started late in Cesarean section. Our department also started research and control of Cesarean section in 2006. Some scholars have carried out good studies on Cesarean section; it is considered that the actual investment in Cesarean section today is mainly concentrated in the repeated pregnancy after Cesarean Section, RCS, huge fetus (Macrosomia), and less amniotic fluid (Oligohydramnios and Fetal Distress, Social Factors, Social Factors, etc.), and related medical institutions should be analyzed and have certain effective measures for corresponding indications. This can really reduce the proportion of highertight-bedroom proportion. In summary, due to the contrarity of Cesarean section in the past few years, the maternal Cesarean section has increased rapidly, it is difficult to control, and the Cesarean section is constantly expanding. The main reason for this phenomenon is not just a medical problem or social problems. In this regard, we should analyze the main causes of this phenomenon and conduct a reasonable propaganda for the true indications of Cesarean section and bad disadvantages [4]. On the basis of current research, this paper selects March 2018 and March 2019 in two obstetrics and gynecology hospitals, referred to as hospital A and hospital B. 313 pregnant women were divided into multi-index group and conventional group, while analyzing various indicators of each group of cesarean collection. The results show that the total CNAXE rate was $48.10 \%$ and $39.29 \%$, respectively, for 2018 and 2019, respectively, and the cesarean section of the conventional group was $65.75 \%$ and $63.64 \%$. By contrasting data of multiindex group and conventional group, hospital $\mathrm{B}$ differences were significant $(P<0.05)$, and hospital A difference was extremely significant $(P<0.01)$. In Cesarean section, obstetric sectors can help maternal treatment strategies by monitoring a series of related indicators to reduce Cesarean section and improve prognosis.

\section{Data and Methods}

3.1. General Information. 313 cases of pregnant women from March 2018 to December 2019 in hospital A of obstetrics and gynecology and hospital b of obstetrics and gynecology were selected, including 152 cases divided into 79 cases in multiindependent group and 73 cases in regular group. The age is 22-39 years (average $27.41 \pm 3.53$ ); the pregnancy is $36-42$ weeks, with average of $38.39 \pm 4.35$ weeks. Hospital A had 161 cases: 84 cases of multi-indicator group and 77 cases of regular group, with ages of 20 to 38 years (average 27.14 \pm 2.85 ) and pregnancy of 37-42 weeks (average $39.30 \pm 1.38$ ). The cases of the two hospitals had no history of internal surgery and pelvic stenosis, pregnancy complications, and so forth in the week before birth or before labor, and B-ultrasound examination and fetal heart rate monitoring were performed.

3.2. Checking Method. (1) The grayscale B-ultrasound $(3.5-5.0 \mathrm{MHz}$, the vaginal probe frequency is $6.5 \mathrm{MHz}$ ) and the color Doppler ultrasonic diagnostic instrument (the probe frequency is $3.5 \mathrm{MHz}$ ), respectively, are used, and the selected pregnant woman is examined. In the multi-indicator group, pregnant women take the stone frame and put the vaginal probe plug, the head is applied to the pocket and then put into the vagina, and then the 
double top diameter (BPD), head circumference (HC), discontinuation (AD), abdominal circumference (AC), femur length (FL), femoral skin fat thickness (FTH), fetus, amniotic fluid, cervical length (CVL), and uterine scars thickness are measured. In the conventional group, pregnant women are subjected to an end-length position and BPD, FL, fetus, and amniotic fluid index are measured. (2) Both groups use the fetal heart monitor to conduct half-hour monitoring of the pregnant women to obtain NST scoring materials [5-7].

\subsection{Measurement Indicators}

3.3.1. Predicting a Huge Indicator. The multi-index group is predicted by $B P D \geq 9.5 \mathrm{~cm}, \mathrm{FL} \geq 7.5 \mathrm{~cm}$, and $\mathrm{AC} \geq 37 \mathrm{~cm}$, and the conventional group is only predicted with $B P D \geq 9.5 \mathrm{~cm}$ and $\mathrm{FL} \geq 7.5 \mathrm{~cm}$.

3.3.2. Umbilical Inspection of the Neck. According to the standard of Obstetrics and gynecology: abdominal or vaginal B-ultrasound examination, there are obvious indentation on the skin around the umbilical cord. Or color Doppler examination showed umbilical cord blood flow signal in the longitudinal section of fetal neck, and umbilical cord blood flow around fetal neck in the transverse section.

3.3.3. Fetal Distress Indicator. The diagnostic criteria of "obstetrics and gynecology" were used, and Apgar score was used. The infants were scored at 1,5 , and 10 minutes after birth. $0-3$ points were severe asphyxia, and $4-7$ points were mild asphyxia

3.3.4. Cervical Maturity Indicator. According to the literature, it is defined as the cervidal length of $30 \mathrm{~mm}$.

3.3.5. Uterine Scar Thickness. The measurement method of "Ultrasonic Diagnosis" of Utility Obstetrics and Gynecology is used in the edge of the fetus to the fetus. The distance $>30 \mathrm{~mm}$ is standard [8-10].

\subsection{Statistical Method. The count data is used in $\chi^{2}$ test.}

\section{Results}

Comparison of the giant childhood delivery outcomes in each group of hospital is shown in Table 1. Comparison of the endings of the two hospitals in each group is shown in Table 2. Comparison of the fetches of the fetuses of the two hospitals is shown in Table 3.

4.1. Determination of Cervical Maturity. Hospital B in the multi-indicator group uses vaginal B-ultrasound to measure the length of 79 pregnant women, including 25 cases of cervical length $\geq 30 \mathrm{~mm}, 18$ cases of Tongzhani $(72.00 \%), 7$ cases of waters $<30 \mathrm{~mm}$, all vaginal Childbirth $(28.00 \%)$; hospital $\mathrm{A}$ in the multi-independent group measures the length of the cervix in 84 pregnant women, with 31 cases having a length $\geq 30 \mathrm{~mm}, 26$ cases of cesarean section, accounting for $83.87 \%$; cervical length $<30 \mathrm{~mm}$ in 5 cases, all vaginal delivery, accounting for $16.13 \%$ [11-13].

4.2. Scar Thickness of Uterus. There were 12 cases of the 79 cases in the multi-index group of hospital B suffering from scar uterus: 5 cases had scar thickness $\leq 30 \mathrm{~mm}$, all Cesarean section (41.67\%), and 7 cases had scar thickness $>30 \mathrm{~mm}$, all of which were vaginal delivery (58.33\%). Among the 79 cases in the multi-index group of hospital B, 12 cases had scar uterus, 5 cases had scar thickness $\leq 30 \mathrm{~mm}$, all of which were cesarean section (41.67\%), and 7 cases had scar thickness $>30 \mathrm{~mm}$, and all of which were vaginal delivery (58.33\%).

4.3. Comparison of Delivery Outcomes in Different Fetal Positions. Comparison of the outcomes of the two hospitals in various groups of orientation is shown in Table 4.

4.4. Comparison of Childbirth Endings. The percentages of Cesarean section in the two hospitals were $48.10 \%$ and $39.29 \%$, respectively, and the percentages of Cesarean section in the conventional group were $65.75 \%$ and $63.64 \%$, respectively, and there is no significant difference between multi-index group and conventional group in the two hospitals. In a comparison of Cesarean section, hospital B has significant differences $(P<0.05)$, and hospital $\mathrm{A}$ has extremely significant difference $(P<0.01)$. See Table 5 [14-16].

\section{Discussion}

5.1. Monitoring and Childbirth. As can be seen from Table 1, the diagnosis rate of multi-independent groups in the two hospitals is higher, $75 \%$ and $83.33 \%$, respectively, and the Cesarean section is $33.33 \%$ and $26.67 \%$, respectively; but in the regular group the diagnosis rate is only $33.33 \%$ and $46.15 \%$. The Cesarean section is higher, $100 \%$ and $83.33 \%$. The percentage in the conventional group is much higher than that in the multi-indicator group, perhaps with doctors concerns that huge children may cause difficulty in production and maternal and child injury, especially the injury of brachial plexus neurons caused by shoulder dystocia. However, the literature reports that, due to the high accuracy of huge children and the literatism of the huge children, the choice of Cesarean section does not reduce the incidence of parent and child's complications, while Cesarean section may cause bleeding, infection, thrombosis outside the neonatal asphyxia, the existence of uterine scars, the uterus rupture, perforation, and so forth when the woman is prone to pregnancy and artificial abortion and the perforations. It is suggested that the clinician should accurately predict the situation of huge children. It is tightly observed on the production of huge children. When the production process is normal, try to choose vaginal delivery to ensure the safety of the mother and the child [17-19]. 
TABLE 1: Comparison of the giant childhood delivery outcomes in each group of hospitals.

\begin{tabular}{|c|c|c|c|c|c|c|c|}
\hline Unit & Group & $\begin{array}{c}\text { Number of } \\
\text { cases }\end{array}$ & $\begin{array}{l}\text { Predicted value } \\
\text { (cases) }\end{array}$ & $\begin{array}{c}\text { Measured value } \\
\text { (cases) }\end{array}$ & $\begin{array}{c}\text { Coincidence rate } \\
(\%)\end{array}$ & $\begin{array}{c}\text { Cesarean delivery } \\
\text { (cases, \%) }\end{array}$ & $\begin{array}{c}\text { Vaginal delivery } \\
\text { (cases, \%) }\end{array}$ \\
\hline \multirow{2}{*}{$\begin{array}{l}\text { Hospital } \\
\text { B }\end{array}$} & $\begin{array}{l}\text { Multiattribute } \\
\text { group }\end{array}$ & 79 & 12 & 9 & 75.00 & $3(33.33)$ & $6(66.67)$ \\
\hline & Regular group & 73 & 9 & 3 & 33.33 & $3(100.00)$ & $0(0.00)$ \\
\hline \multirow{2}{*}{$\begin{array}{l}\text { Hospital } \\
\text { A }\end{array}$} & $\begin{array}{l}\text { Multiattribute } \\
\text { group }\end{array}$ & 84 & 18 & 15 & 83.33 & $4(26.67)$ & $11(73.33)$ \\
\hline & Regular group & 77 & 13 & 6 & 46.15 & $5(83.33)$ & $1(16.67)$ \\
\hline
\end{tabular}

TABLE 2: Comparison of the endings of the two hospitals in each group.

\begin{tabular}{|c|c|c|c|c|c|c|c|}
\hline Unit & Group & $\begin{array}{c}\text { Number of } \\
\text { cases }\end{array}$ & $\begin{array}{c}\text { Predicted value } \\
\text { (cases) }\end{array}$ & $\begin{array}{l}\text { Measured value } \\
\text { (cases) }\end{array}$ & $\begin{array}{c}\text { Coincidence rate } \\
(\%)\end{array}$ & $\begin{array}{c}\text { Cesarean delivery } \\
\text { (cases, \%) }\end{array}$ & $\begin{array}{c}\text { Vaginal delivery } \\
\text { (cases, \%) }\end{array}$ \\
\hline \multirow{2}{*}{$\begin{array}{l}\text { Hospital } \\
\text { B }\end{array}$} & $\begin{array}{l}\text { Multiattribute } \\
\text { group }\end{array}$ & 79 & 29 & 25 & 86.21 & $9(36.00)$ & $16(64.00)$ \\
\hline & Regular group & 73 & 13 & 5 & 38.46 & $4(80.00)$ & $1(20.00)$ \\
\hline \multirow{2}{*}{$\begin{array}{l}\text { Hospital } \\
\text { A }\end{array}$} & $\begin{array}{l}\text { Multiattribute } \\
\text { group }\end{array}$ & 84 & 37 & 34 & 91.89 & $10(29.41)$ & $24(70.59)$ \\
\hline & Regular group & 77 & 19 & 7 & 36.84 & $5(71.43)$ & $2(28.57)$ \\
\hline
\end{tabular}

TABLE 3: Comparison of the fetches of the fetuses of the two hospitals.

\begin{tabular}{|c|c|c|c|c|c|c|c|}
\hline Unit & Group & $\begin{array}{c}\text { Number of } \\
\text { cases }\end{array}$ & $\begin{array}{l}\text { Predicted value } \\
\text { (cases) }\end{array}$ & $\begin{array}{c}\text { Measured value } \\
\text { (cases) }\end{array}$ & $\begin{array}{c}\text { Coincidence rate } \\
(\%)\end{array}$ & $\begin{array}{c}\text { Cesarean delivery } \\
(\text { cases, } \%)\end{array}$ & $\begin{array}{c}\begin{array}{c}\text { Vaginal delivery } \\
\text { (cases, \%) }\end{array} \\
\end{array}$ \\
\hline \multirow{2}{*}{$\begin{array}{l}\text { Hospital } \\
\text { B }\end{array}$} & $\begin{array}{l}\text { Multiattribute } \\
\text { group }\end{array}$ & 79 & 39 & 35 & 89.74 & $14(40.00)$ & $21(60.00)$ \\
\hline & Regular group & 73 & 28 & 9 & 32.14 & $7(77.78)$ & $2(22.22)$ \\
\hline \multirow{2}{*}{$\begin{array}{l}\text { Hospital } \\
\text { A }\end{array}$} & $\begin{array}{l}\text { Multiattribute } \\
\text { group }\end{array}$ & 84 & 37 & 34 & 91.89 & $11(32.35)$ & $23(67.65)$ \\
\hline & Regular group & 77 & 19 & 8 & 42.10 & $6(75.00)$ & $2(25.00)$ \\
\hline
\end{tabular}

TABLE 4: Comparison of the outcomes of the two hospitals in various groups of orientation (example).

\begin{tabular}{|c|c|c|c|c|c|c|c|c|c|}
\hline \multirow{2}{*}{ Unit } & \multirow{2}{*}{ Group } & \multirow{2}{*}{$\begin{array}{c}\text { Number of } \\
\text { cases }\end{array}$} & \multicolumn{2}{|c|}{$\begin{array}{l}\text { Occiput anterior } \\
\text { position }\end{array}$} & \multicolumn{2}{|c|}{$\begin{array}{l}\text { Occiput transverse } \\
\text { position }\end{array}$} & \multicolumn{2}{|c|}{$\begin{array}{l}\text { Occiput posterior } \\
\text { position }\end{array}$} & \multirow{2}{*}{$\begin{array}{c}\text { Caesarean } \\
\text { delivery rate } \\
(\%)\end{array}$} \\
\hline & & & $\begin{array}{c}\text { Cesarean } \\
\text { delivery }\end{array}$ & $\begin{array}{l}\text { vaginal } \\
\text { delivery }\end{array}$ & $\begin{array}{c}\text { Cesarean } \\
\text { delivery }\end{array}$ & $\begin{array}{l}\text { vaginal } \\
\text { delivery }\end{array}$ & $\begin{array}{c}\text { Cesarean } \\
\text { delivery }\end{array}$ & $\begin{array}{l}\text { vaginal } \\
\text { delivery }\end{array}$ & \\
\hline \multirow{2}{*}{$\begin{array}{l}\text { Hospital } \\
\text { B }\end{array}$} & $\begin{array}{l}\text { Multiattribute } \\
\text { group }\end{array}$ & 79 & 12 & 37 & 14 & 5 & 10 & 1 & 48.10 \\
\hline & Regular group & 73 & 26 & 17 & 17 & 8 & 5 & 0 & 65.75 \\
\hline \multirow{2}{*}{$\begin{array}{l}\text { Hospital } \\
\text { A }\end{array}$} & $\begin{array}{l}\text { Multiattribute } \\
\text { group }\end{array}$ & 84 & 13 & 32 & 15 & 14 & 5 & 5 & 39.29 \\
\hline & Regular group & 77 & 25 & 14 & 10 & 10 & 14 & 4 & 63.64 \\
\hline
\end{tabular}

TABle 5: Comparison of two hospital delivery outcomes (example, \%).

\begin{tabular}{|c|c|c|c|c|c|c|}
\hline Unit & Group & Number of cases & Cesarean delivery & Vaginal delivery & $\chi^{2}$ value & $P$ value \\
\hline \multirow{2}{*}{ Hospital B } & Multiattribute group & 79 & $38(48.10)$ & $41(51.90)$ & \multirow{2}{*}{4.812} & \multirow{2}{*}{$<0.05$} \\
\hline & Regular group & 73 & $48(65.75)$ & $25(34.25)$ & & \\
\hline \multirow{2}{*}{ Hospital A } & Multiattribute group & 84 & $33(39.29)$ & $51(60.71)$ & \multirow{2}{*}{9.532} & \multirow{2}{*}{$<0.01$} \\
\hline & Regular group & 77 & $49(63.64)$ & $28(36.36)$ & & \\
\hline
\end{tabular}


5.2. Umbilical Covered Neck Monitoring. As can be seen from Table 2, the diagnosis rate of multi-independent group in the two hospitals was $86.21 \%$ and $91.89 \%$, and the Cesarean section rate was $36.00 \%$ and $29.41 \%$; the regular group's diagnosed compliance rate was $38.46 \%$ and $36.84 \%$, and, for Cesarean section, the yield has reached $80.00 \%$ and $71.43 \%$, and the difference in Cesarean section rate in the two groups was significant $(P<0.05)$. The main reason for the significant increase in the number of cesarean section is that many pregnant women are afraid of fetal distress and abnormal production in the process of vaginal delivery, and obstetricians are also worried that there will be unexpected risks in the process of production, and umbilical cord around the neck is one of the indications of cesarean section. However, for pregnant women with umbilical cord around the neck without other indications of cesarean section, they should be encouraged to have a vaginal trial. It is not necessary to choose cesarean section because of a single umbilical cord around the neck. It is only necessary to consider cesarean section when umbilical cord around the neck affects production. In addition, adopting active and reliable premonitoring can not only effectively adjust the clinical progress of fetus with umbilical cord around neck but also have certain significance for reducing the current increasing rate of Cesarean section [20].

5.3. Fetal Distress Monitoring. As shown in Table 3, the cesarean section rates of the multi index groups in the two hospitals were $40.00 \%$ and $32.35 \%$, respectively. The cesarean section rates in the routine group were $77.78 \%$ and $75.00 \%$, respectively, which were higher than those in the multi-index group. However, the diagnostic coincidence rate in the multi-index group was higher than that in the routine group. The main reasons for the high cesarean section rate in the routine group are the inconsistent understanding of fetal distress by medical staff, different diagnostic scales, and the increasing probability of cesarean section due to fetal distress in order to avoid unnecessary medical disputes.

\subsection{Detection of Cervical Length and Uterine Scar Thickness.} Since the cervical length is an important indicator of cervical maturation, the vaginal measurement of the length of the cervix is a more objective ideal approach to a certain extent avoiding subjective factors. Through objective images and specific data measurements, the estimated results of traditional vaginal examination are replaced, and the vaginal ultrasound measurement does not require a filling bladder, and the display rate is $100 \%$, so the cervical length can be used to predict delivery. Vaginal B-ultrasound was used in 25 cases and 31 cases in the two hospitals in this project, including 18 and 26 cases of cesarean section, accounting for $72.00 \%$ and $83.87 \%$, which is similar to the situation reported in the literature. In addition, the measurement of the thickness of the uterine scar has a certain guiding effect on the decision of the pregnancy delivery. At present, in most cases, full-term pregnant women with scarred uterus mostly use cesarean section, and people with vaginal trial conditions rarely carry out vaginal trial, which is related to many medical disputes, tense medical relations, and limited technical level of medical personnel. Studies have shown that trial delivery is more favorable than cesarean section. For maternal women who become pregnant after Cesarean section, after the diabolic evidence of vaginal delivery, the opportunity to give trial production is to improve the success rate of vaginal delivery and reduce Cesarean section [21, 22].

\section{Conclusions}

In summary, reducing Cesarean section is a systematic project, and there is a significant need to adopt comprehensive interventions and even pay attention to the whole society. This paper makes a series of indicators for maternity, such as the monitoring of fetal size, cervical maturity, and uterine scar thickness, further reducing the risk of vaginal delivery, reducing misdiagnosis of Cesarean section, and thereby reducing Cesarean section. The results show that the total CNAXE rate was $48.10 \%$ and $39.29 \%$, respectively, for 2018 and 2019, respectively, and the cesarean section of the conventional group was $65.75 \%$ and $63.64 \%$. By contrasting data of multi-index group and conventional group, hospital $\mathrm{B}$ differences were significant $(P<0.05)$, and hospital A difference was extremely significant $(P<0.01)$. To a certain extent, the hospital should strengthen postpartum health publicity and education. Through the mission to let the mothers and their families understand the pros and cons of various production methods, the abnormal situation is found in time, timely treatment, and avoiding serious complications. Strengthening the psychological care of pregnant women in daily monitoring can make husband or relatives accompany pregnant women during childbirth and reduce pregnant women's fear, so that the production process is more smooth.

\section{Data Availability}

The data used to support the findings of this study are available from the corresponding author upon request.

\section{Conflicts of Interest}

The authors declare that they have no conflicts of interest.

\section{References}

[1] R. Malakooti, A. Z. Ayop, B. Maulianda, K. Muradov, and D. Davies, "Integrated production optimisation and monitoring of multi-zone intelligent wells," Journal of Petroleum Exploration and Production Technology, vol. 10, no. 1, pp. 159-170, 2020.

[2] L. Zhang, L. Zhang, M. Li et al., "A cluster-randomized field trial to reduce cesarean section rates with a multifaceted intervention in shanghai, China," BMC Medicine, vol. 18, no. 1, p. 27, 2020.

[3] O. Gassama, B. Biaye, B. Taoufiki, N. A. Faye, and J. C. Moreau, "Fetal instrumental extractions at the maternity section of the dakar nabil choucair health centre (Senegal) in 2017: epidemio-clinical aspects, indications and prognosis," Open Journal of Obstetrics and Gynecology, vol. 10, no. 3, pp. 390-399, 2020. 
[4] P. Kranke, S. Weibel, M. Sitter, P. Meybohm, and T. Girard, "Geburtshilfliche Anästhesie während der SARS-CoV-2-Pandemie: Übersicht der Handlungsempfehlungen," AINS Anästhesiologie · Intensivmedizin · Notfallmedizin · Schmerztherapie, vol. 55, no. 04, pp. 266-274, 2020.

[5] C. Yang and D. Ouyang, "Variation trend and influential factors for cesarean section rate in a general hospital in changsha from 2008 to 2017. Zhong nan da xue xue bao," Yi xue ban = Journal of Central South University, vol. 44, no. 3, pp. 334-337, 2019.

[6] G. Hui, Z. Mai-Liang, and R. Hong-Fen, "Effect of transcutaneous electrical acupoint stimulation on recovery of gastrointestinal function after cesarean section," Zhongguo zhen jiu = Chinese acupuncture \& moxibustion, vol. 39, no. 3, pp. 259-262, 2019.

[7] M. Borys, B Potr-Studzińska, M Wiech et al., "Transversus abdominis plane block and quadratus lumborum block did not reduce the incidence or severity of chronic postsurgical pain following cesarean section: a prospective, observational study," Anaesthesiology Intensive Therapy, vol. 51, no. 4, pp. 257-261, 2019.

[8] Y. Gao, M. Guo, C. Du, H. Zhang, and H. Zhang, "Clinical study of ultrasound-guided transversus abdominis plane block for analgesia after cesarean section," Medicine, vol. 98, no. 41, Article ID e17542, 2019.

[9] Y. Changfang, X. Yao, and J. Wang, "Dextrocardia with complete av block and the implantation of a temporary pacemaker before cesarean section: a case report," Medicine, vol. 98, no. 17, Article ID e15211, 2019.

[10] A. M. Zaconeta, A. C. Oliveira, F. S. Estrela et al., "Intrauterine device insertion during cesarean section in women without prenatal contraception counseling: lessons from a country with high cesarean rates," Revista Brasileira de Ginecologia e Obstetrícia : revista da Federacao Brasileira das Sociedades de Ginecologia e Obstetricia, vol. 41, no. 8, pp. 485-492, 2019.

[11] X. Xia, Z. Zhou, S. Shen et al., "Effect of a two-stage intervention package on the cesarean section rate in guangzhou, China: a before-and-after study," PLoS Medicine, vol. 16, no. 7, Article ID e1002846, 2019.

[12] W. S. Dong, Y. Kim, B. Hong, S. H. Yoon, and S. Youn, "Effect of fentanyl on nausea and vomiting in cesarean section under spinal anesthesia: a randomized controlled study," Journal of International Medical Research, vol. 47, no. 10, pp. 4798-4807, 2019.

[13] Y. Ma, X. Luo, X. Jiang, H. Liu, and L. Wu, "Perioperative patient blood management during parallel transverse uterine incision cesarean section in patient with pernicious placenta previa," Medicine, vol. 99, no. 35, Article ID e21916, 2020.

[14] M. Sheikh, G. Nelson, S. L. Wood, and P. A. Metcalfe, "Surgical errors and complications following cesarean section in the United States," American Journal of Obstetrics \& Gynecology MFM, vol. 2, no. 1, Article ID 100071, 2019.

[15] A. Jafarzadeh, M. Hadavi, G. Hassanshahi, M. Rezaeian, and A. Sarkoohi, "Cesarean or cesarean epidemic?" Archives of Iranian Medicine, vol. 22, no. 11, pp. 663-670, 2019.

[16] C. Kunqian, G. Chen, and F. Zhang, "Application of ultrasound-guided balloon occlusion in cesarean section in 130 cases of sinister placenta previa," Journal of Interventional Medicine, vol. 3, no. 01, pp. 46-49, 2020.

[17] L. Bautista and R. George, "Dexmedetomidine for every cesarean delivery maybe not?" Obstetric Anesthesia Digest, vol. 40, no. 2, p. 106, 2020.

[18] Y. Du, L. Wang, G. Wu, X. Lei, W. Li, and J. Lv, "Anesthesia and protection in an emergency cesarean section for pregnant woman infected with a novel coronavirus: case report and literature review," Journal of Anesthesia, vol. 34, no. 4, pp. 613-618, 2020.

[19] L. Cegolon, G. Mastrangelo, O. M. Campbell et al., "Length of stay following cesarean sections: a population based study in the friuli venezia giulia region (north-eastern Italy), 20052015," PLoS One, vol. 14, no. 2, Article ID e0210753, 2019.

[20] X. Wu, Z. Zhang, H. Chang, and Q. Huang, "A data-driven gross domestic product forecasting model based on multiindicator assessment," IEEE Access, no. 99, p. 1, 2021.

[21] L. Liang, B. G. Ridoutt, W. Wu et al., "A multi-indicator assessment of peri-urban agricultural production in beijing, China," Ecological Indicators, vol. 97, no. FEB, pp. 350-362, 2019.

[22] S. A. Ganeriwal, G. A. Ryan, N. C. Purandare, and C. N. Purandare, "Examining the role and relevance of the critical analysis and comparison of cesarean section rates in a changing world," Taiwanese Journal of Obstetrics and Gynecology, vol. 60, no. 1, pp. 20-23, 2021. 